\title{
CONGENITAL CORNEAL OPACITIES $* \dagger$ IN A PATIENT WITH RIEGER'S ANOMALY AND DOWN'S SYNDROME
}

BY

\author{
A. J. DARK AND T. H. KIRKHAM \\ From the Department of Ophthalmology, Royal Hospital, Sheffield
}

THIS report concerns a child with Down's syndrome (mongolism) and bilateral congenital corneal opacities born into a family affected through three generations by Rieger's anomaly.

\section{Case Report}

A female infant (V.6, see Fig. 5) was brought to the hospital at the age of 2 months because her mother had noticed that both eyes had been "white" since birth. Pregnancy had been uneventful; no viral infection or contact with rubella during the first trimester had occurred. Birth had been normal and the child was thriving. At no time had there been photophobia or lacrimation.

Examination.-Down's syndrome was suggested by the presence of macroglossia, muscular hypotony, and a single transverse palmar crease on the right hand. Epicanthus was not present.

The child's attention was attracted by bright lights.

RIGHT EYE (Figs 1 and 2): A dense creamy-white ectatic disc-like opacity $9.5 \mathrm{~mm}$. in diameter was present in the centre of the cornea. The corneal periphery $2 \mathrm{~mm}$. wide was deeply vascularized with radially running vessels; it was translucent and clear enough to see blue iris tissue lying close to its posterior surface.

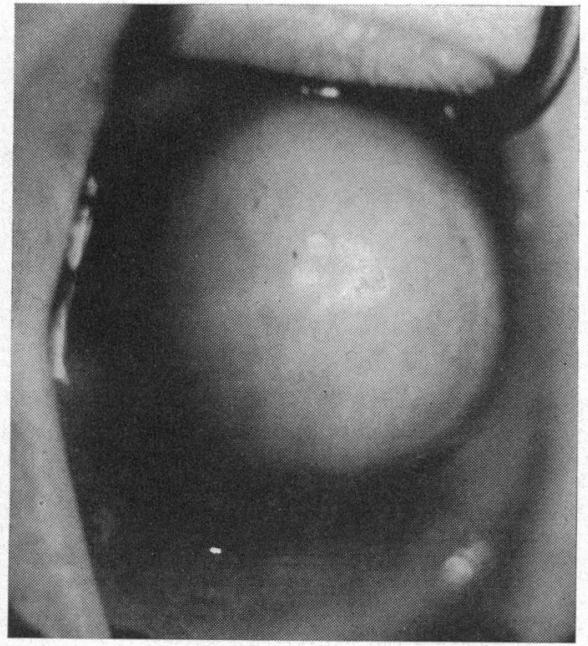

FIG. 1.-Case V.6. Right cornea, showing dense white central opacity.

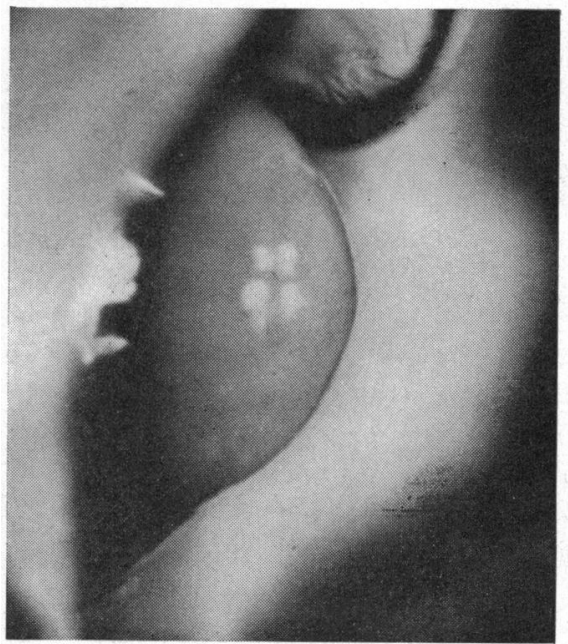

FIG. 2.-As Fig. 1, but profile demonstrating globular pseudoectasia.

* Received for publication July $27,1967$.

† Address for reprints: T. H. Kirkham, The Royal Hospital, West Street, Sheffield, S1 3SR 
Examination with a $\times 8$ loupe revealed numerous vertically disposed blood vessels distributed more or less evenly throughout the opacity which was otherwise homogeneous in consistency. These vessels splayed out into arborizations beneath the surface epithelium. The opacity did not transilluminate and therefore it was impossible to determine the location and reaction of the pupil. The sclera was bluish in the ciliary region. Ocular tension was felt to be within normal limits digitally (Schiøtz, 17.3/5.5 and $18 \cdot 5 / 7 \cdot 5 \mathrm{~mm}$. Hg). The horizontal corneal diameter was $13 \cdot 5 \mathrm{~mm}$.

LEFT EYE: The left cornea (Fig. 3) was, for the most part, a translucent bluish white colour, but a dense annular opacity (the presumed site of mesodermal irido-corneal adhesion) surrounded a relatively clear central zone about $3 \mathrm{~mm}$. in diameter. Diascleral transillumination correlated the latter appearance with the underlying pupil. No direct light reaction was present. Transillumination showed that the iris pigment epithelium, however, stopped short about $2 \mathrm{~mm}$. from the limbus. Peripherally the anterior chamber was very shallow, the plane of the iris being parallel to that of the cornea. Deep radial vascularization of the whole cornea was present on this side. In profile the cornea was seen to be cone-shaped (Fig. 4), the base of the cone extending towards the limbus. A scleral band corresponding to the ciliary body was bluish. The ocular tension was thought to be moderately elevated by digital examination (Schiøtz 20.6/5.5 and 21.9/7.5 mm. $\mathrm{Hg}$ ). The horizontal corneal diameter was $11.5 \mathrm{~mm}$.

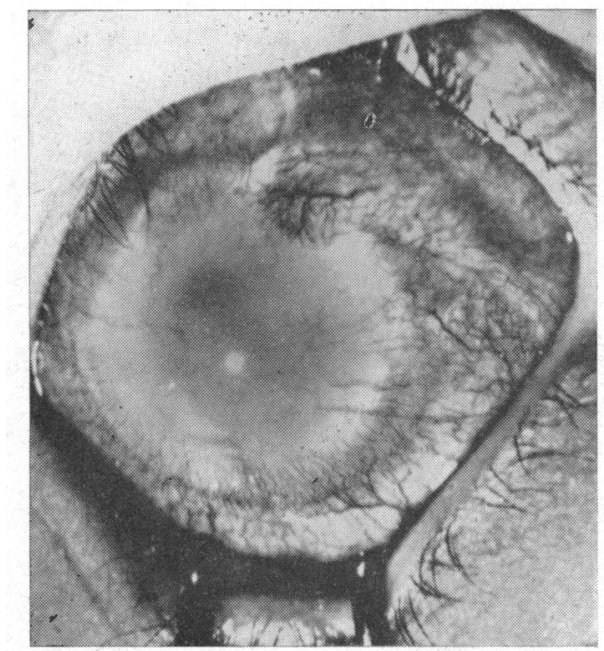

FIG. 3.-Case V.6. Left cornea, showing translucent central zone surrounded by dense ring opacity.

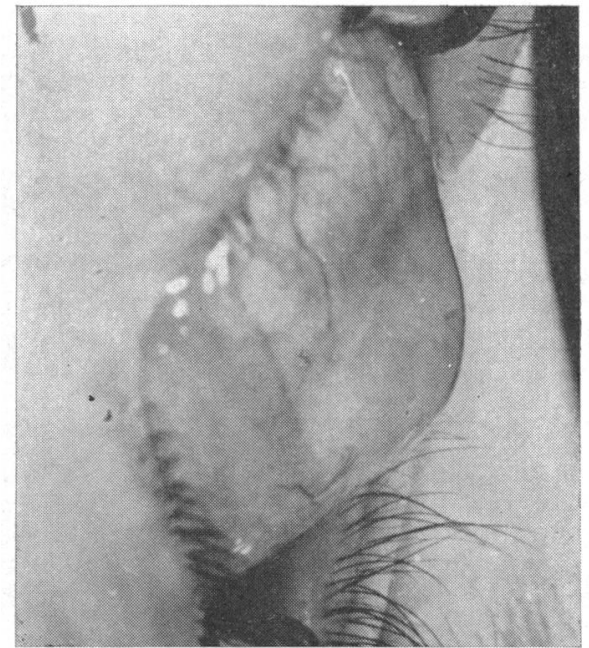

Fig. 4.-As Fig. 3, but profile to show conical shape of cornea.

Investigations. - A buccal smear showed sex chromatin positive cells as in a normal female and chromosome analysis indicated trisomy in the 21-22 group. The Wassermann reaction and Kahn and treponemal immobilization tests were negative. No mucopolysaccharides were found in the urine and a urinary aminoacid chromatogram was normal.

The child's father was found to have Rieger's anomaly with associated glaucoma, and Rieger's anomaly was demonstrated in certain members of three generations of his family who were examined (Fig. 5, page 633).

Subsequent history.-A diagnosis of bilateral congenital glaucoma was made and goniopuncture of both eyes was undertaken.

The right corneal diameter has not changed over the past 18 months although the central opacity has increased in diameter from $9.5 \mathrm{~mm}$. to $11 \mathrm{~mm}$. Right lamellar keratoplasty was undertaken. In spite of the large size of the graft $(11 \cdot 1 \mathrm{~mm}$.) no technical difficulties were encountered. The 


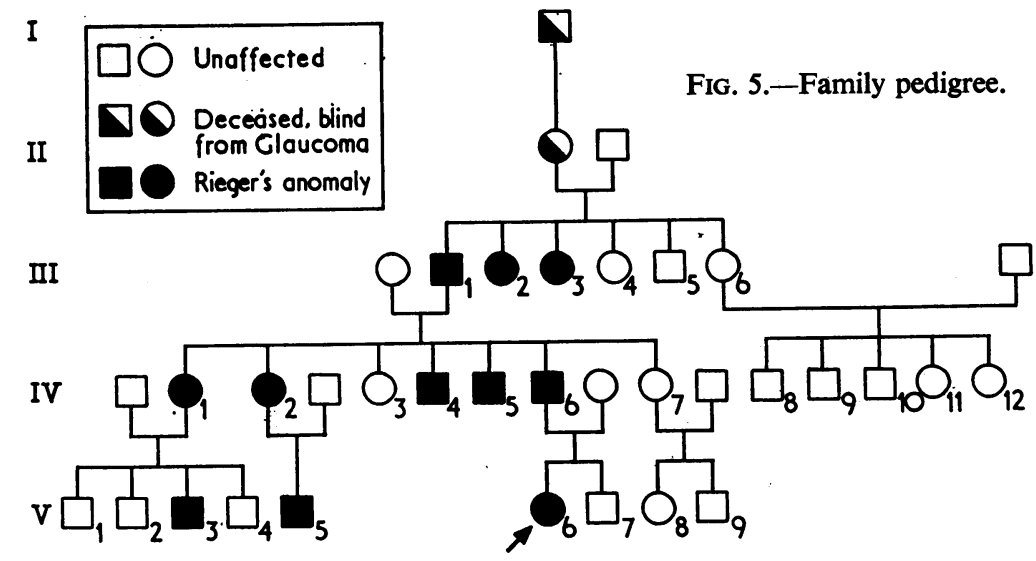

deep layers of the trephined area thus displayed showed a central ring opacity surrounding a central clear zone, an appearance very like that noted in the left cornea. The curvature of the graft bed was the same as that of the corneal periphery. The graft is clear and well tolerated at the present time-10 weeks post-operatively.

The ocular tension in the left eye was subsequently controlled by a series of transconjunctival cyclodiathermies. The left corneal diameter increased to $12.5 \mathrm{~mm}$. but has remained stationary for the past 3 months.

\section{Microscopy of Disc removed at Keratoplasty}

The disc removed at keratoplasty was fixed in formol saline and bisected, one half being embedded in paraffin and the other being used for frozen section. Routine histological methods were applied to paraffin sections. The Sudan black method for fat and Bielschowsky's stain for nerve fibres were used on frozen sections.

Anterior epithelium.-Considerable hyperplasia of the anterior epithelium was present; there was no keratinization of superficial squames (Fig. 6).

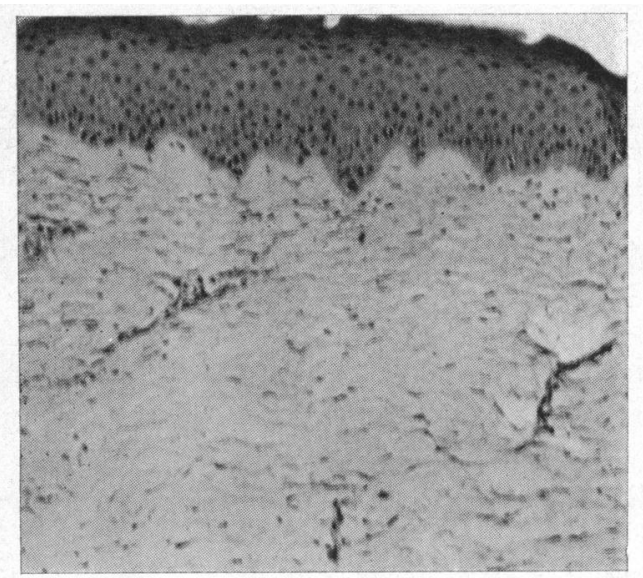

Fig. 6.-Section of disc removed at keratoplasty, showing hyperplasia of epithelium, undulating Bowman's membrane, and vascularization of stroma. Haematoxylin and eosin. $\times 100$.

Stroma.-The anterior limiting membrane was absent (Periodic acid-Schiff staining) and Bowman's membrane, although present, was undulating. The stroma was greatly thickened centrally and heavily vascularized. Its cell population was not increased apart 
from a moderate number of perivascular mast cells, nor was there any other evidence of inflammation. There was no abnormal lipid present and nerve fibres of normal appearance and distribution were present throughout the anterior stroma.

\section{Discussion}

When it was viewed through the translucent periphery of the right cornea, the anterior chamber was seen to be very shallow, the plane of the iris shelving towards the corneal centre. The central opaque ring opacity displayed in the deep layers of this cornea at keratoplasty doubtless coincided with the site of adherence of iris collarette mesoderm to the cornea. Such collarette adhesions with corneal opacification have been previously noted in Rieger's anomaly (Paufique, Étienne, and Bonnet, 1950; Reese and Ellsworth, 1966). The opacities may be one of the three following types:

(1) Annular oedema in the overlying layers proceeding to permanent ring opacification in the stroma;

(2) Total central opacification which may be either truly ectatic; or,

(3) As in the right eye of the present patient, a pseudo-ectasia.

It is not the purpose of this paper to present the findings in the child's paternal antecedents who are affected by Rieger's anomaly (see Fig. 5). Particular mention is made, however, of the ocular findings in Case III.1 because of their relevance to the interpretation of the cone-shaped left cornea of our patient.

Case III.1, a man aged 79 years, had no perception of light in either eye. The right cornea was deeply vascularized and showed advanced cone-shaped ectasia with a dense central opacity. The anterior chamber was of moderate depth and there was no adhesion between the iris and this opacity. The iris mesoderm was markedly atrophic with insertion of its deep lamella into a prominent Schwalbe's line which itself was displaced towards the centre of the cornea. A blue scleral band was present. The left eye was in an advanced phthisical state.

Keratoconus associated with Rieger's anomaly has been noted previously (Paufique and others, 1950; Klien, 1961; Haye, Pouliquen, Coscas, and Blanck, 1965). On the other hand it has not been recorded as a congenital defect in mongolism. It thus seems probable that keratoconus in our patient is associated with the former disorder.

There is little literature on the treatment of ring opacities. Visual improvement following synechiotomy has been recorded in one patient and microscopic examination of nine eyes afflicted with this condition indicates that in the majority the posterior pole is normal (Reese and Ellsworth, 1966). Thus it is possible to speculate that surgical treatment may offer a means of salvaging vision in such patients.

Glaucoma, if present, must be controlled, and when annular oedema is present, synechiotomy may be used to facilitate sealing of the posterior corneal defect by allowing endothelial hyaline membrane production. Finally, there is evidence from the immediate result in our patient that lamellar keratoplasty in cases of total opacity offers a prospect of restoring vision.

\section{Summary}

(1) The clinical appearances of bilateral congenital corneal opacities in an infant associated with annular adhesion of the iris collarette mesoderm to the posterior corneal surface are described. This condition has been related to Rieger's anomaly which was present in the paternal antecedents in three generations. 
(2) Keratoconus on the left side of our patient has been related to Rieger's anomaly rather than to mongolism and was present in one other affected member of the family.

(3) Treatment is discussed. Lamellar keratoplasty on one eye has been initially successful; histology of the disc is described.

\section{REFERENCES}

Haye, C., Pouliquen, Y., Coscas, G., and Blanck, C. (1965). Bull. Soc. Ophtal. Fr., 65, 296.

KLIEN, B. A. (1961). v. Graefes Arch. Ophthal., 164, 12.

Paufique, L., Étienne, R., and Bonnet, J. L. (1950). Ann. Oculist. (Paris), 183, 81.

Reese, A. B., and Ellsworth, R. M. (1966). Arch. Ophthal. (Chicago), 75, 307. 